\title{
Article
}

\section{Design of Promising aza-BODIPYs for Bioimaging and Sensing}

\author{
Dmitry Merkushev ${ }^{1}$, Olga Vodyanova ${ }^{1}$, Felix Telegin ${ }^{1}$, Pavel Melnikov ${ }^{2}{ }^{\mathbb{D}}$, Nikolay Yashtulov ${ }^{2}$ \\ and Yuriy Marfin ${ }^{1, *}$ \\ 1 Department of Inorganic Chemistry, Ivanovo State University of Chemistry and Technology, \\ Sheremetevsky pr. 10, 153010 Ivanovo, Russia; ununnamed911@gmail.com (D.M.); \\ osvodyanova@gmail.com (O.V.); f.telegin@mail.ru (F.T.) \\ 2 M. V. Lomonosov Institute of Fine Chemical Technologies, MIREA-Russian Technological University, \\ 119571 Moscow, Russia; melnikovsoft@mail.ru (P.M.); yashtulovna@mail.ru (N.Y.) \\ * Correspondence: marfin@isuct.ru
}

Citation: Merkushev, D.; Vodyanova, O.; Telegin, F.; Melnikov, P.; Yashtulov, N.; Marfin, Y. Design of Promising aza-BODIPYs for Bioimaging and Sensing. Designs 2022, 6, 21. https://doi.org/ $10.3390 /$ designs 6020021

Academic Editor: Jerzy

Malachowski

Received: 7 January 2022

Accepted: 18 February 2022

Published: 1 March 2022

Publisher's Note: MDPI stays neutral with regard to jurisdictional claims in published maps and institutional affiliations.

Copyright: (C) 2022 by the authors. Licensee MDPI, Basel, Switzerland. This article is an open access article distributed under the terms and conditions of the Creative Commons Attribution (CC BY) license (https:// creativecommons.org/licenses/by/ $4.0 /)$.

\begin{abstract}
The obtainment of new luminophores for molecular sensorics of biosystems is becoming one of the urgent tasks in the field of chemical synthesis. The solution to each practical problem imposes its own limitations in the design of new structures with practically useful properties. The relationship between the structure and spectral properties is still to be unveiled. Three aza-BODIPY complexes with substituents of different natures were studied using time-resolved and steady-state fluorescence and absorption spectroscopy. The solvatochromic properties of aza-BODIPYs were studied with the use of a combined polyparametric approach and analysis by chemoinformatics methods for the first time. It was found that red shift of aza-BODIPY dyes was due to the increase of their structural lability. Predictive and experimental methods showed that the investigated aza-BODIPYs exhibited a positive solvatochromic effect, in contrast to classic BODIPYs (bearing C in the meso-position of the dipyrromethene core), which represents the negative solvatochromic properties. Spectral maxima in the area of the therapeutic window, low and predictable solvatochromism, and the ability to fine-tune the spectral characteristics make the investigated aza-BODIPYs promising scaffolds for the construction of bioengineering devices. Generalizations on the aza-BODIPYs' design patterns were made in accordance with further bioimaging applications.
\end{abstract}

Keywords: aza-BODIPY; molecular design; fluorescence; absorption; time-resolved fluorescence; solvatochromism

\section{Introduction}

Today, clinical diagnostic methods based on fluorescence spectroscopy and molecular sensors are being actively developed. Scientists keep looking for new fluorescent molecules that can act as selective sensors to measure the intracellular and intercellular parameters of biological systems [1]. These compounds could be used for the qualitative and quantitative assessment of the ongoing biochemical processes [2]. Synthetic and biogenic luminophores are actively used as sensors and markers of biological processes and conditions [3,4]. They can also be used in the design of biomimetic materials [5-7] or smart materials [8-11], allowing one to explore and adapt their properties for a specific task. Spectral techniques allow one to track the localization of functional molecules [12], determining the characteristics of their molecular environment [13] and, in some cases, detailing the mechanisms of the processes occurring in the organism [14]. At the same time, the use of fluorophores requires, as a rule, fine-tuning of their spectral and photophysical characteristics [4,15]. The position of the absorption and emission bands is important. The most promising for sensing applications is the spectral range of $650-900 \mathrm{~nm}$, the so-called "therapeutic window" [16], where the absorption and self-fluorescence of tissues and organs is minimal. In addition, compound design should ensure the selectivity (for sensor 
applications) or inertness (for labeling) of compounds to changes in the molecular environment due to the implementation of a limited number of mechanisms for intramolecular and intermolecular energy transfer [17].

Boron dipyrrin complexes (BODIPYs) are among the most promising synthetic fluorophores, which have intense fluorescent characteristics [18], are resistant to aggressive environmental factors $[19,20]$, and can also be chemically modified to solve specific applied problems [21]. These compounds exhibit red-near-infrared fluorescence and are able to carry up to six desired substituents [22], realizing their potential as effective fluorescent sensors. The most studied at the moment are the compounds with the absorption and fluorescence maxima in the region of 480-530 $\mathrm{nm}$, and some of the compounds are available for commercial purchase. However, the chemistry of BODIPY is actively developing, and every year, new compounds and groups of substances appear that are applicable to solve problems in medicine [23], sensorics, including biosensorics [24], and in the design of new optical energy converters [25-27]. The list of measured parameters is extensive and includes temperature [28], the viscosity [29] of intracellular and intercellular fluids, the shape and volume of organelles [30], the presence of heavy metal ions [31], and the acidity of the medium [32]. The study of these parameters is closely connected with solvent polarity and dye solvatochromism [33-37]. On the one hand, solvatochromic dyes are excellent environment-sensitive probes for polarity [38], viscosity [39], and molecular order [40]. On the other hand, solvatochromism may not be preferred in biological studies due to the non-uniformity of biological liquids, making it harder to isolate the target signal in a complex medium. The latter leads to the abundance of articles dedicated to qualitative, but not quantitative measurements. However, very few papers have studied the influence of the substituents on the solvatochromism of BODIPY dyes, and to our knowledge, none of them have been on aza-BODIPYs.

The use of aza-BODIPYs as components of sensing instruments is less widespread. At the same time, for applications in the field of bioengineering, medicine, and precise controlling systems, systemic information about new promising chemical compounds is important- the spectral properties and their effects when varying the solvate environment [41] and the possible toxic effect [42,43]. In this regard, within the framework of this work, several new boron dipyrrin luminophores were proposed, the spectral characteristics in a wide range of solvents are described, and a prognostic interpretation of the properties of the compounds is given. We hope that the results of this work will be of interest not only to chemists, but also to a wide range of researchers and engineers who consider aza-BODIPYs as promising components for the design of new sensors and molecular devices.

\section{Materials and Methods}

In this work, three aza-BODIPY dyes were studied, which were synthesized previously $[44,45]$ and differ in their functional substituents along the periphery (Figure 1):

4,4-difluoro-1,7-diphenyl-3,5-dithienyl-4-boron-3a,4a,8-triaza-s-indacene (1); 4,4-difluoro-1,7-diphenyl-3,5-ditolyl-4-boron-3a,4a,8-triaza-s-indacene (2); 4,4-difluoro-1,3,5,7-tetrathienyl-4-boron-3a,4a,8-triaza-s-indacene (3).

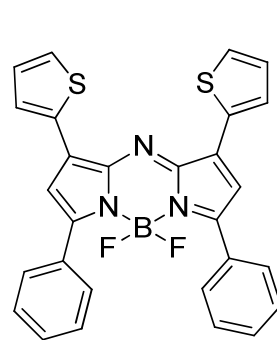

1

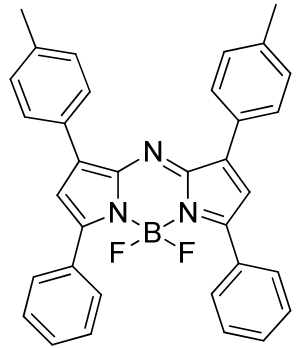

2

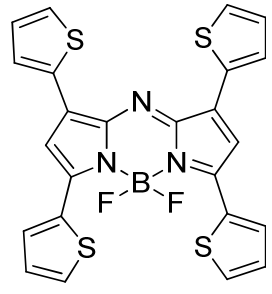

3

Figure 1. Structural formula of investigated aza-BODIPYs. 
aza-BODIPYs 1 and 3 were selected in order to understand the influence of the electrondonating substituents and their number on the photophysical properties of aza-BODIPYs. aza-BODIPY 2 was used as a reference compound, bearing ordinary aromatic substituents.

The measurements were carried out in organic solvents, using dilute solutions of compounds with a given concentration. The optical density at the absorption maximum did not exceed 0.1 in order to avoid the effects of aggregation and an internal filter. The measurements were carried out in quartz cuvettes with a thickness of the light-absorbing solution layer of $10 \mathrm{~mm}$.

Electronic absorption spectra (EAS) were recorded in the range of 190-1100 nm on an Aquilon SF-104 spectrophotometer controlled by the UV-Win 5.1.0 software package.

Fluorescence spectra were obtained on a Cary Eclipse Varian-Agilent fluorescence spectrometer with the Cary Eclipse Scan Application 1.1 software.

The decay curves of the excited state of the molecules were obtained by counting single photons with the time correlation on a PicoQuant FluoTime 300 instrument with the EasyTau 2 software and a laser wavelength of $450 \mathrm{~nm}, 500 \mathrm{~nm}$, or $600 \mathrm{~nm}$. Additionally, the decay curves were measured using an optical setup assembled at the Hedley Gordon Single Molecule Laboratory, The University of Glasgow, Scotland.

All solvents used were chemically pure and produced by ChemMed (Moscow, Russia) and Sigma Aldrich (Moscow, Russia).

In order to correlate the photophysical properties of the aza-BODIPYs with the parameters of the solvate microenvironment, the method of linear regression analysis was used. When solving the equation with respect to one property of the system with known values of the set of solvent parameters, the equation has the form:

$$
\mathrm{X}=\mathrm{X}_{0}+\mathrm{a} \cdot \mathrm{A}+\mathrm{b} \cdot \mathrm{B}+\mathrm{c} \cdot \mathrm{C}+\cdots,
$$

where:

$\mathrm{X}$ is the physicochemical parameter of the compound in a given solvent;

$X_{0}$ is the value of a given physical and chemical property in the gas phase or inert solvent; $\mathrm{A}, \mathrm{B}$, and $\mathrm{C}$ are independent parameters of the solvent, describing various mechanisms of interaction between the solvent and the solute;

$\mathrm{a}, \mathrm{b}$, and $\mathrm{c}$ are coefficients characterizing the contribution from the parameters $\mathrm{A}, \mathrm{B}, \mathrm{C}$ of the solvent to the investigated property.

For the regression analysis, the sets of the Kamlet-Taft [46] and Catalan [47] parameters were used, the values of which varied from 0 to 1 (Table 1 ).

Table 1. Parameters of individual organic solvents: a set of Catalan parameters (SP-polarity; SPP—polarizability; SA—acidity; SB—basicity); a set of Kamlet/Taft parameters ( $\pi$ —polarity/polarizability, $\alpha$-proton-donor properties, $\beta$-electron-donor properties).

\begin{tabular}{cccccccc}
\hline \multirow{2}{*}{ Solvent } & \multicolumn{3}{c}{ Kamlet-Taft Parameters } & \multicolumn{3}{c}{ Catalan Parameters } \\
\cline { 2 - 7 } & $\boldsymbol{\pi}$ & $\mathbf{B}$ & $\boldsymbol{\alpha}$ & $\mathbf{S P}$ & SPP & SA & SB \\
\hline Acetone & 0.71 & 0.48 & 0.08 & 0.651 & 0.907 & 0.000 & 0.475 \\
Benzene & 0.59 & 0.10 & 0.00 & 0.793 & 0.270 & 0.000 & 0.124 \\
Hexane & -0.08 & 0.00 & 0.00 & 0.616 & 0.000 & 0.000 & 0.056 \\
Dimethyl sulfoxide & 1.00 & 0.76 & 0.00 & 0.830 & 1.000 & 0.072 & 0.647 \\
Dimethylformamide & 0.88 & 0.69 & 0.00 & 0.759 & 0.977 & 0.031 & 0.613 \\
Dichloromethane & 0.82 & 0.00 & 0.30 & 0.761 & 0.769 & 0.040 & 0.178 \\
Methanol & 0.60 & 0.62 & 0.93 & 0.608 & 0.904 & 0.605 & 0.545 \\
Propanol & 0.52 & 0.90 & 0.78 & 0.658 & 0.748 & 0.367 & 0.782 \\
Tetrachloromethane & 0.28 & 0.00 & 0.00 & 0.768 & 0.000 & 0.000 & 0.044 \\
Toluene & 0.54 & 0.11 & 0.00 & 0.782 & 0.284 & 0.000 & 0.128 \\
Chloroform & 0.58 & 0.00 & 0.44 & 0.783 & 0.614 & 0.047 & 0.071 \\
\hline
\end{tabular}


Table 1. Cont.

\begin{tabular}{ccccccccc}
\hline \multirow{2}{*}{ Solvent } & \multicolumn{3}{c}{ Kamlet-Taft Parameters } & \multicolumn{3}{c}{ Catalan Parameters } \\
\cline { 2 - 7 } & $\boldsymbol{\pi}$ & $\mathbf{B}$ & $\boldsymbol{\alpha}$ & $\mathbf{S P}$ & $\mathrm{SPP}$ & SA & SB \\
\hline Cyclohexane & 0.00 & 0.00 & 0.00 & 0.683 & 0.000 & 0.000 & 0.073 \\
Ethanol & 0.54 & 0.77 & 0.83 & 0.633 & 0.783 & 0.400 & 0.658 \\
Ethyl acetate & 0.55 & 0.45 & 0.00 & 0.656 & 0.603 & 0.000 & 0.542 \\
\hline
\end{tabular}

For a systematic analysis of the solvatochromism of aza-BODIPYs, a new semi-empirical approach was used, developed by the senior researcher of the laboratory, Felix Telegin, which was based on the theories of Lippert-Mataga, Bilot-Kavski, Bakhshiev, Liptey, and their special cases [41]. The solvatochromic sensitivity of the dye to the microenvironment can be estimated from the equation for changing the position of absorption and fluorescence bands in a series of solvents:

$$
v_{\mathrm{abs}}-v_{\mathrm{fl}}=-\mathrm{A}\left(v_{\mathrm{abs}}+v_{\mathrm{fl}}\right)+\mathrm{B},
$$

where:

$v_{\mathrm{abs}}$ and $v_{\mathrm{fl}}$ are maxima in the absorption and fluorescence spectra, expressed as wavenumbers, $\mathrm{cm}^{-1}$;

$v_{\mathrm{abs}}-v_{\mathrm{fl}}$ is Stokes' shift, $\mathrm{cm}^{-1}$;

$\mathrm{A}$ is the sensitivity of the fluorophore to the polar environment;

$B$ is the free-term equation.

An experimental estimate of the coefficient A gives a relationship between the dipole moments in the ground $\left(\mu_{\mathrm{g}}\right)$ and excited $\left(\mu_{\mathrm{e}}\right)$ states:

$$
\mathrm{A} \approx \frac{\mu_{\mathrm{e}}-\mu_{\mathrm{g}}}{\mu_{\mathrm{e}}+\mu_{\mathrm{g}}} .
$$

However, it should be noted that the use of an equation that includes the difference in wavenumbers is not optimal, due to the doubling of the statistical error in comparison with the coefficients for individual absorption and fluorescence bands. It is preferable to use equations that are derived linear combinations of the original equality:

$$
\begin{gathered}
v_{\mathrm{abs}}=\frac{1-\mathrm{A}}{2}\left(v_{\mathrm{abs}}+v_{\mathrm{fl}}\right)+\frac{B}{2}=A_{\mathrm{abs}}\left(v_{\mathrm{abs}}+v_{\mathrm{fl}}\right)+\mathrm{B}_{\mathrm{abs}}, \\
v_{\mathrm{fl}}=\frac{1+\mathrm{A}}{2}\left(v_{\mathrm{abs}}+v_{\mathrm{fl}}\right)-\frac{B}{2}=A_{\mathrm{fl}}\left(v_{\mathrm{abs}}+v_{\mathrm{fl}}\right)-\mathrm{B}_{\mathrm{fl}} .
\end{gathered}
$$

The calculation of the ratio of the coefficients $\mathrm{A}_{\mathrm{abs}}$ and $\mathrm{A}_{\mathrm{fl}}$ allows us to determine the ratio of the dipole moments of the analyzed compounds more accurately:

$$
\frac{\mathrm{A}_{\mathrm{abs}}}{\mathrm{A}_{\mathrm{fl}}}=\frac{1-\mathrm{A}}{1+\mathrm{A}}=\frac{\mu_{\mathrm{g}}}{\mu_{\mathrm{e}}} .
$$

\section{Results}

The spectral and photophysical properties of aza-BODIPYs 1-3 were studied in a number of solvents of different natures (Figure 2). Due to the low solubility of the studied compounds in water, this solvent was not included. The use of compounds in biosensorics will require DMSO as a co-solvent or the immobilization of aza-BODIPYs into micelles and/or functional materials [12,48]. Compared to classic BODIPYs, the aza-BODIPY 1-3's electronic transitions were observed in the red and near-infrared (NIR) regions. The maxima of the absorption and fluorescence spectra were recorded in the ranges of 650-750 nm and $670-770 \mathrm{~nm}$, respectively. It was shown that the introduction of thienyl into the 1,3,5,7-positions of the dipyrrin nucleus shifted the absorption and fluorescence maxima bathochromically: aza-BODIPY $2\left(\lambda_{\mathrm{abs}}=652 \mathrm{~nm}, \lambda_{\mathrm{fl}}=675 \mathrm{~nm}\right) \rightarrow$ dithienyl-aza-BODIPY 1 
$\left(\lambda_{\mathrm{abs}}=681 \mathrm{~nm}, \lambda_{\mathrm{fl}}=720 \mathrm{~nm}\right) \rightarrow$ tetrathienyl-aza-BODIPY $3\left(\lambda_{\mathrm{abs}}=742 \mathrm{~nm}, \lambda_{\mathrm{fl}}=758 \mathrm{~nm}\right)$. Accordingly, the position of the spectral maxima was greatly influenced by the substitution of nitrogen for the meso-carbon atom, the expansion of the conjugated system, and the introduction of alkyl or aromatic substituents into the $\alpha-, \beta$-positions of the pyrrole rings of the dipyrrin.

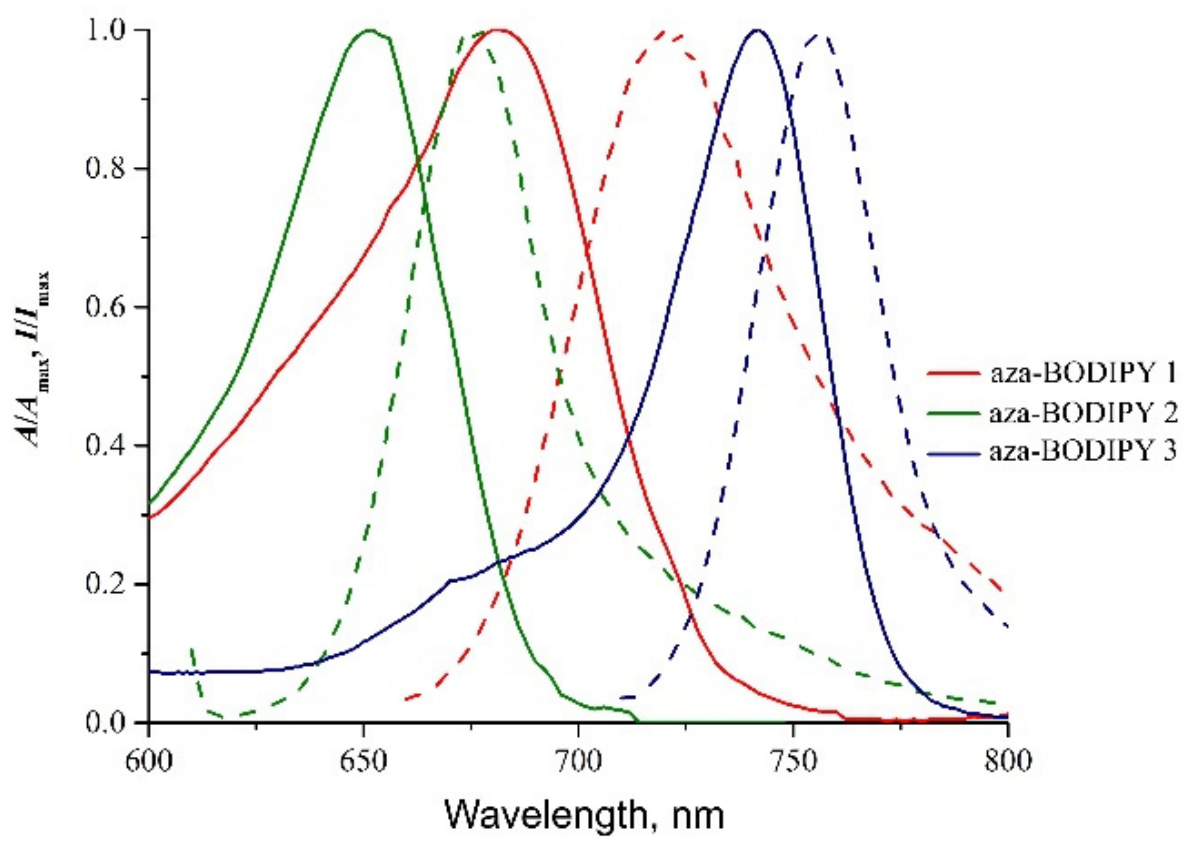

Figure 2. Normalized absorption (solid lines) and normalized fluorescence (dotted lines) spectra of the investigated aza-BODIPYs in DCM.

The fluorescence decay curves were recorded for the investigated compounds at the wavelength of the maximum fluorescence in various solvents (Figure 3). It was found that aza-BODIPY 1 had a narrower distribution compared to structural analogs 2 and 3.

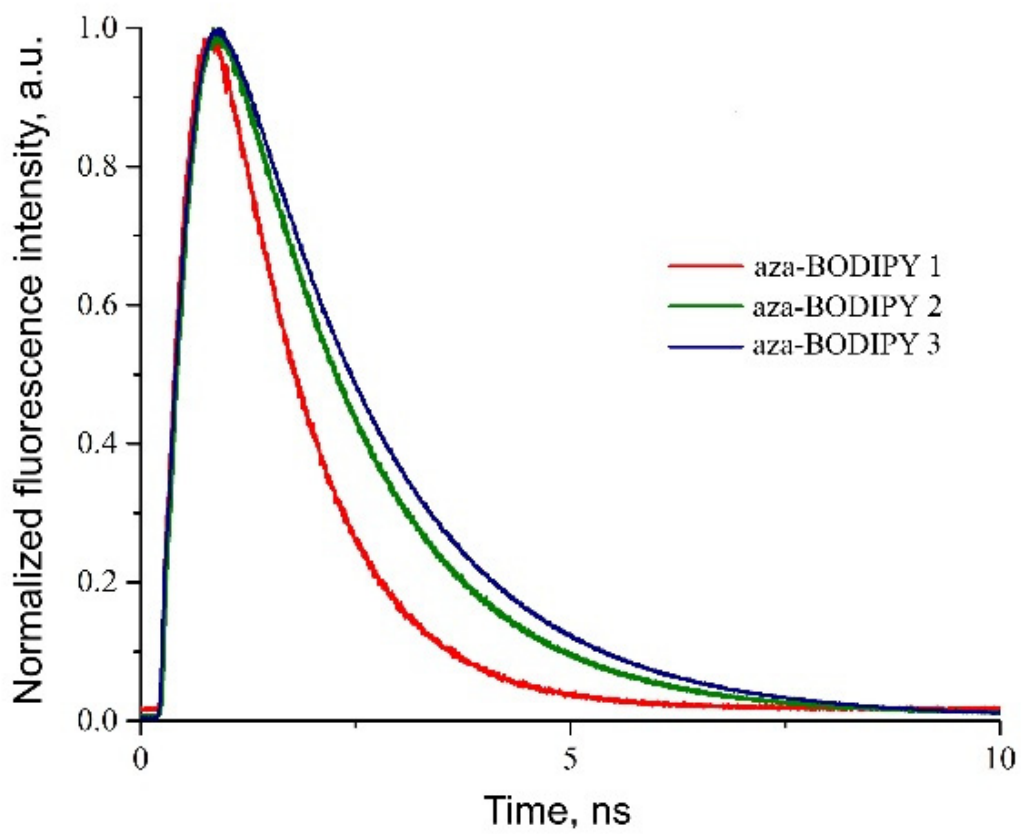

Figure 3. Fluorescence decay curves of aza-BODIPYs 1-3 in toluene. 
The obtained fluorescence lifetimes were consistent with the literature (Table 2). The aza-BODIPYs were characterized by rather low values of fluorescence quantum yields $(\varphi)$ : 0.10 for Compound 1 and 0.11 for Compound 3 (solvent: dichloromethane; comparison dye: rhodamine 101), and the fluorescence lifetimes were in the range of 1-2 ns [45,49-51].

Table 2. Spectral characteristics of aza-BODIPYs 1-3 in individual organic solvents: $\lambda_{\text {abs }}$-absorption maximum wavelength, $\mathrm{nm} ; \lambda_{\mathrm{fl}}$-wavelength of fluorescence maximum, $\mathrm{nm} ; \Delta \lambda$-Stokes' shift, $\mathrm{nm}$; $\tau$-fluorescence lifetime at $293 \mathrm{~K}, \mathrm{~ns}, \Phi$-fluorescence quantum yield. Fluorescence was excited at $600 \mathrm{~nm}$.

\begin{tabular}{|c|c|c|c|c|c|}
\hline \multicolumn{6}{|c|}{ aza-BODIPY 1} \\
\hline & $\lambda_{\mathrm{abs}}, \mathrm{nm}$ & $\lambda_{\mathrm{fl}}, \mathrm{nm}$ & $\Delta \lambda, \mathrm{nm}$ & $\tau, \mathrm{ns}$ & $\Phi$ \\
\hline Acetone & 678.0 & 722.0 & 44.0 & 0.97 & 0.016 \\
\hline Benzene & 684.0 & 719.0 & 35.0 & 0.97 & 0.028 \\
\hline Hexane & 674.0 & 704.0 & 30.0 & 0.98 & 0.026 \\
\hline Dimethyl sulfoxide & 693.0 & 733.0 & 40.0 & 1.07 & 0.015 \\
\hline Dimethylformamide & 688.0 & 731.0 & 43.0 & 0.80 & 0.014 \\
\hline Dichloromethane & 681.0 & 720.0 & 39.0 & 1.02 & 0.017 \\
\hline Methanol & 678.0 & 717.0 & 39.0 & 0.64 & 0.030 \\
\hline Propanol & 679.0 & 716.0 & 37.0 & 0.98 & 0.022 \\
\hline Tetrachloromethane & 680.0 & 713.0 & 33.0 & 1.09 & 0.027 \\
\hline Toluene & 685.0 & 717.0 & 32.0 & 1.05 & 0.030 \\
\hline Chloroform & 682.0 & 717.0 & 35.0 & 1.08 & 0.025 \\
\hline Cyclohexane & 674.0 & 709.0 & 35.0 & 0.73 & 0.024 \\
\hline Ethanol & 678.0 & 718.0 & 40.0 & 1.06 & 0.020 \\
\hline \multicolumn{6}{|c|}{ aza-BODIPY 2} \\
\hline & $\lambda_{\mathrm{abs}}, \mathrm{nm}$ & $\lambda_{\mathrm{fl}}, \mathrm{nm}$ & $\Delta \lambda, \mathrm{nm}$ & $\tau, \mathrm{ns}$ & $\Phi$ \\
\hline Acetone & 650.0 & 673.0 & 23.0 & 0.65 & 0.036 \\
\hline Benzene & 656.0 & 678.0 & 22.0 & 1.39 & 0.085 \\
\hline Hexane & 646.0 & 667.0 & 21.0 & 0.97 & 0.062 \\
\hline Dimethyl sulfoxide & 662.0 & 686.0 & 24.0 & 0.91 & 0.050 \\
\hline Dimethylformamide & 656.0 & 681.0 & 25.0 & 0.81 & 0.094 \\
\hline Dichloromethane & 652.0 & 675.0 & 23.0 & 0.87 & 0.054 \\
\hline Methanol & 648.0 & 672.0 & 24.0 & 0.67 & 0.101 \\
\hline Propanol & 648.0 & 671.0 & 23.0 & 0.78 & 0.064 \\
\hline Tetrachloromethane & 652.0 & 674.0 & 22.0 & 1.30 & 0.080 \\
\hline Toluene & 656.0 & 679.0 & 23.0 & 1.61 & 0.096 \\
\hline Chloroform & 654.0 & 675.0 & 21.0 & 1.71 & 0.116 \\
\hline Cyclohexane & 648.0 & 670.0 & 22.0 & 1.02 & 0.068 \\
\hline \multicolumn{6}{|c|}{ aza-BODIPY 3} \\
\hline & $\lambda_{\text {abs, }}, \mathrm{nm}$ & $\lambda_{\mathrm{fl}}, \mathrm{nm}$ & $\Delta \lambda, \mathrm{nm}$ & $\tau, \mathrm{ns}$ & $\Phi$ \\
\hline Acetone & 735.0 & 749.0 & 14.0 & 1.77 & 0.114 \\
\hline Benzene & 743.0 & 759.0 & 16.0 & 1.97 & 0.291 \\
\hline Hexane & 730.0 & 742.0 & 12.0 & 1.85 & 0.121 \\
\hline Dimethyl sulfoxide & 753.0 & 768.0 & 15.0 & 1.79 & 0.086 \\
\hline Dimethylformamide & 748.0 & 762.0 & 14.0 & 1.61 & 0.098 \\
\hline Dichloromethane & 742.0 & 758.0 & 16.0 & 1.91 & 0.128 \\
\hline Methanol & 739.0 & 751.0 & 12.0 & 1.18 & 0.091 \\
\hline Propanol & 738.0 & 750.0 & 12.0 & 1.46 & 0.087 \\
\hline Tetrachloromethane & 737.0 & 752.0 & 15.0 & 2.16 & 0.117 \\
\hline Toluene & 743.0 & 757.0 & 14.0 & 1.83 & 0.143 \\
\hline Chloroform & 741.0 & 756.0 & 15.0 & 1.99 & 0.102 \\
\hline Cyclohexane & 731.0 & 744.0 & 13.0 & 1.68 & 0.153 \\
\hline Ethanol & 739.0 & 751.0 & 12.0 & 1.34 & 0.093 \\
\hline
\end{tabular}


Luminescence decay curves were obtained for all investigated compounds in solvents of different polarities at the wavelength of the fluorescence maximum $\left(\lambda_{\mathrm{fl}}, \mathrm{nm}\right)$, as well as at longer wavelengths $\left(\lambda_{\mathrm{fl}}+20 \mathrm{~nm}\right)$ and shorter wavelengths $\left(\lambda_{\mathrm{fl}}-10 \mathrm{~nm}\right)$. Based on the data obtained, the values of the lifetimes of the excited state of the molecules were calculated (Table 3). For all the dyes, the absence of the dependence of the gradients of the curves and fluorescence lifetime on the detection wavelength is shown. Thus, the excitation of the studied molecules occurred not in a cascade manner, but through a single vertical transition, and significant geometric changes and intermolecular interactions of the excited state were not observed in comparison with the ground state.

Table 3. Fluorescence lifetimes of aza-BODIPYs 1-3, measured at different wavelengths in cyclohexane, methanol, and toluene: $\lambda_{\text {det }}$-detection wavelength, nm; $\tau$-fluorescence lifetime at $293 \mathrm{~K}$, ns.

\begin{tabular}{|c|c|c|c|c|c|c|}
\hline & \multicolumn{2}{|c|}{ aza-BODIPY 1} & \multicolumn{2}{|c|}{ aza-BODIPY 2} & \multicolumn{2}{|c|}{ aza-BODIPY 3} \\
\hline & $\lambda_{\text {det }}, \mathrm{nm}$ & $\tau, \mathrm{ns}$ & $\lambda_{\mathrm{det}}, \mathrm{nm}$ & $\tau, \mathrm{ns}$ & $\lambda_{\mathrm{det}}, \mathrm{nm}$ & $\tau, \mathrm{ns}$ \\
\hline \multirow{3}{*}{ Hexane } & 699.0 & 0.75 & 660.0 & 0.99 & 734.0 & 1.67 \\
\hline & 709.0 & 0.73 & 670.0 & 1.02 & 744.0 & 1.68 \\
\hline & 729.0 & 0.77 & 690.0 & 0.99 & 764.0 & 1.67 \\
\hline \multirow{3}{*}{ Methanol } & 707.0 & 0.64 & 662.0 & 0.67 & 741.0 & 1.19 \\
\hline & 717.0 & 0.64 & 672.0 & 0.67 & 751.0 & 1.18 \\
\hline & 737.0 & 0.64 & 692.0 & 0.68 & 771.0 & 1.20 \\
\hline \multirow{3}{*}{ Toluene } & 707.0 & 1.11 & 669.0 & 1.60 & 747.0 & 1.83 \\
\hline & 717.0 & 1.05 & 679.0 & 1.61 & 757.0 & 1.83 \\
\hline & 737.0 & 1.07 & 699.0 & 1.60 & 777.0 & 1.83 \\
\hline
\end{tabular}

The solvent nature affected the spectral properties of the compounds. For aza-BODIPYs 1-3, a positive solvatochromic effect was recorded, and the shift of the maxima in the spectra was about 15-20 nm, while for classic BODIPYs, this value usually reaches only 5-8 nm. The main reason that caused the solvatochromic effect, which manifested itself in both the hypsochromic and bathochromic displacement of the absorption maxima of the luminophore, as well as changes in the intensity of absorption and fluorescence, was the differences in the solvation of the compounds by the solvents (solvation only due to van der Waals interactions, the formation of hydrogen bonds, or the stabilization of the excited states of a solute).

In more detail, the solvatochromism of the investigated compounds was assessed using a semiempirical approach according to Liptey's theory (Figure 4). The analyzed aza-BODIPYs had insignificant solvatochromic sensitivity, which explains the low accuracy of determining the coefficient $\mathrm{A}$. The transition to the coefficients for individual absorption and fluorescence bands $\mathrm{A}_{\mathrm{abs}}$ and $\mathrm{A}_{\mathrm{fl}}$ to estimate the ratio of dipole moments in the ground and excited states allowed us to reduce the error to $10 \%$ or less (Table 4 ). The spectral characteristics of the absorption and fluorescence of the studied aza-BODIPYs showed a pronounced red shift, which manifested itself in a negative slope of the dependences $v_{\mathrm{abs}}=\mathrm{f}\left(-\mathrm{A}_{\mathrm{abs}}\left(v_{\mathrm{abs}}+v_{\mathrm{fl}}\right)\right)$ and $v_{\mathrm{fl}}=\mathrm{f}\left(-\mathrm{A}_{\mathrm{fl}}\left(v_{\mathrm{abs}}+v_{\mathrm{fl}}\right)\right)$, respectively. The cumulative synchronous change in these bands was accompanied by an almost constant Stokes' shift, the values of which changed insignificantly with the change of the solvent. Nevertheless, for aza-BODIPYs 1-3, a weak positive solvatochromism was realized $\left(\mathrm{A}_{\mathrm{abs}} / \mathrm{A}_{\mathrm{fl}}<1\right)$. 
aza-BODIPY 1
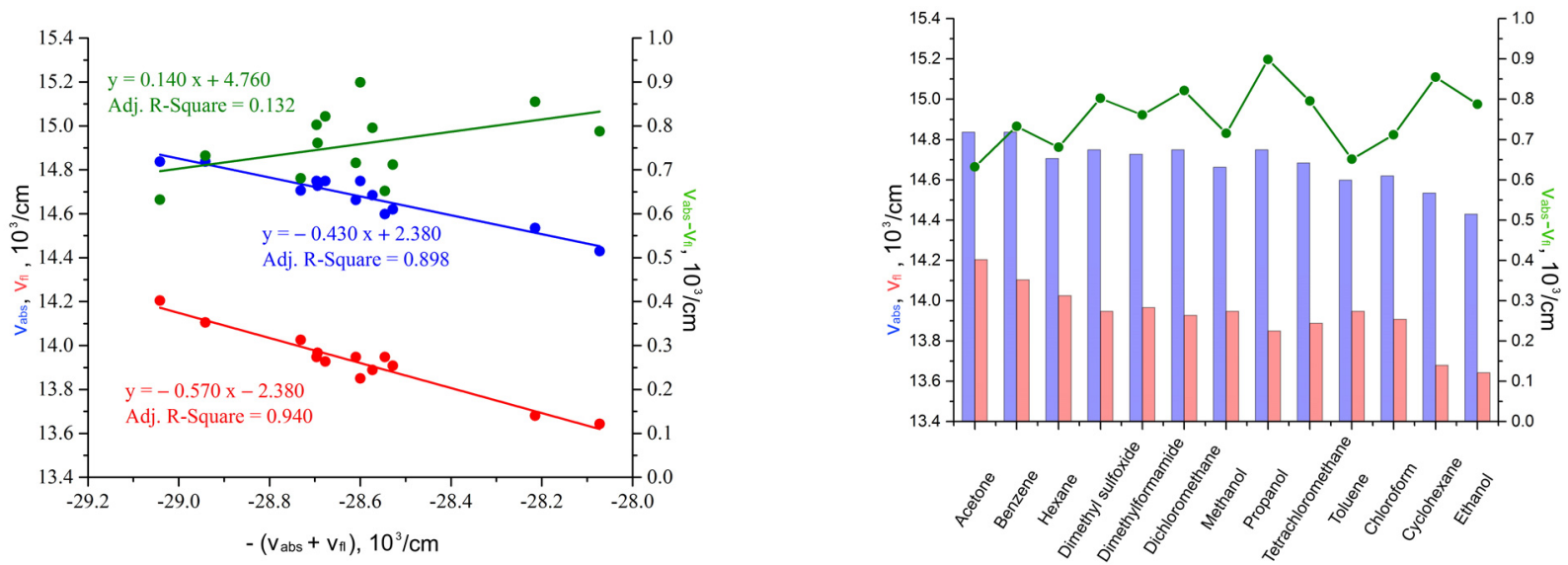

aza-BODIPY 2
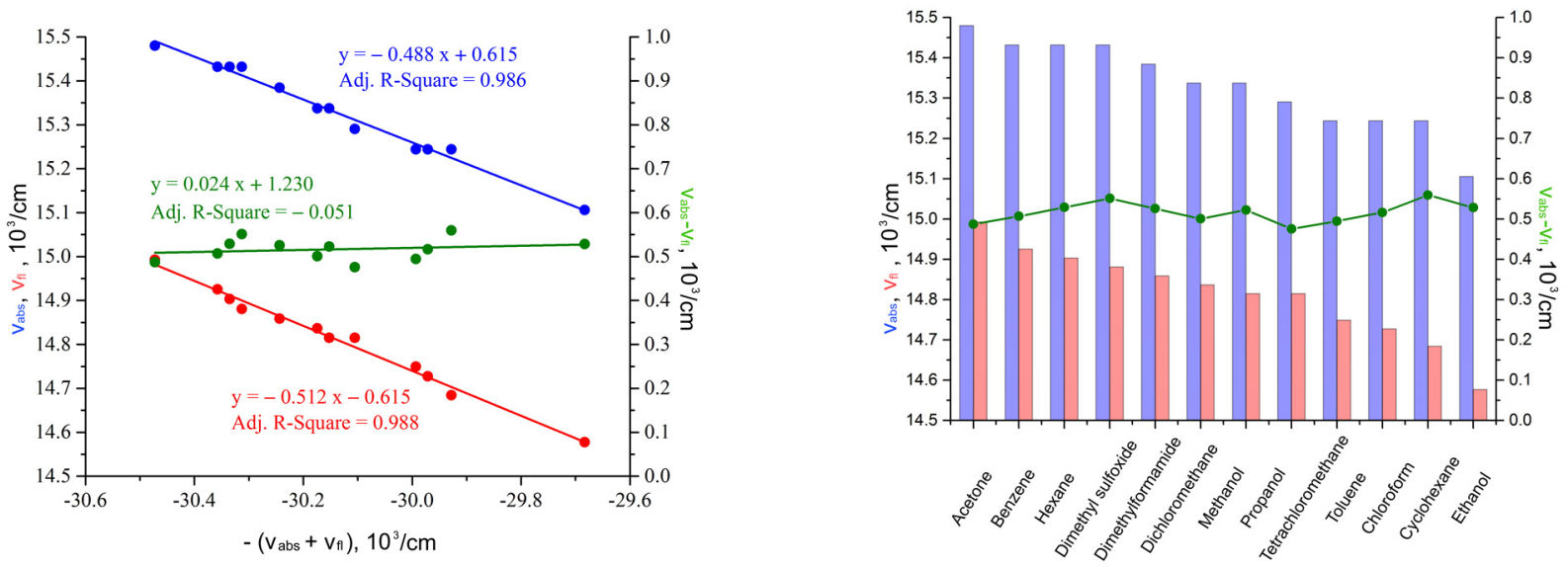

aza-BODIPY 3

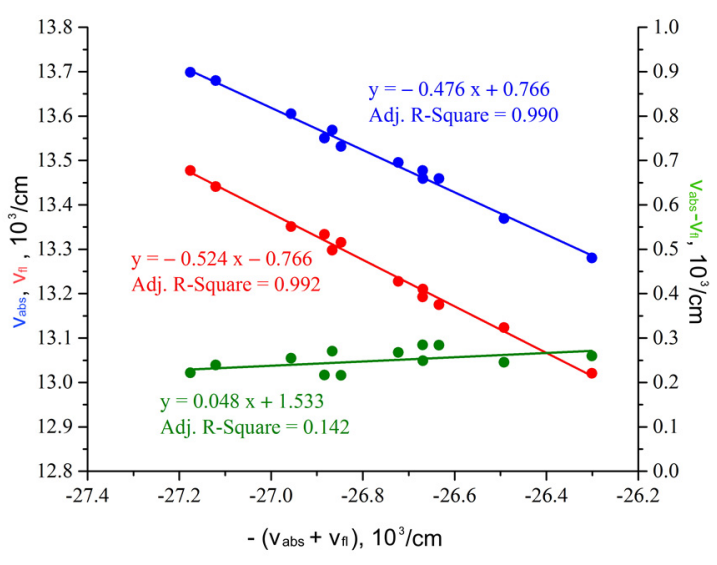

(a)

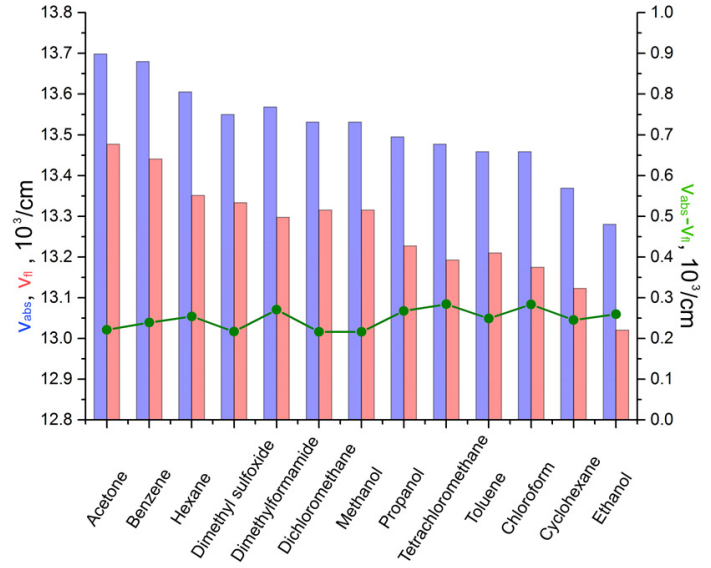

(b)

Figure 4. Dependences of the wavenumbers of the Stokes' shift $v_{\mathrm{Abs}}-v_{\mathrm{Fl}}$, absorption maxima $v_{\mathrm{Abs}}$ and fluorescence $v_{\mathrm{Fl}}$ on (a) negative sum $v_{\mathrm{Abs}}+v_{\mathrm{Fl}} ;(\mathbf{b})$ individual organic solvents to determine the solvatochromic sensitivity parameters $\mathrm{A}, \mathrm{A}_{\mathrm{abs}}$, and $\mathrm{A}_{\mathrm{fl}}$. 
Table 4. Solvatochromic sensitivity parameters.

\begin{tabular}{ccccc}
\hline & $\mathbf{A}_{\mathbf{a b s}}$ & $\mathbf{A}_{\mathbf{f l}}$ & $\mathbf{A}$ & $\mathbf{A}_{\mathbf{a b s}} / \mathbf{A}_{\mathbf{f l}}$ \\
\hline aza-BODIPY 1 & $0.430 \pm 0.042$ & $0.570 \pm 0.042$ & $0.140 \pm 0.083$ & $0.755 \pm 0.091$ \\
aza-BODIPY 2 & $0.488 \pm 0.017$ & $0.512 \pm 0.017$ & $0.024 \pm 0.035$ & $0.954 \pm 0.047$ \\
aza-BODIPY 3 & $0.476 \pm 0.014$ & $0.524 \pm 0.014$ & $0.048 \pm 0.028$ & $0.908 \pm 0.036$ \\
\hline
\end{tabular}

The dependences of the lifetime of the excited state on the individual parameters of solvents: viscosity, dipole moment, normalized Dimroth-Reichardt parameter, or dielectric constant, were not linear, which means the predominant influence of the nature of the solvent and specific interactions on the photophysical characteristics. The correlation of the fluorescence lifetime values with the parameters of Catalan and Kamlet-Taft solvents by the linear regression method also showed low values of the approximation reliability, and the coefficients had an overestimated determination error (Table 5).

Table 5. The value of the reliability of the approximation $\left(R^{2}\right)$ for the linear regression method of the values of the lifetime of the excited state in various solvents.

\begin{tabular}{|c|c|c|c|c|c|}
\hline \multicolumn{6}{|c|}{ Kamlet-Taft Parameters' Regression } \\
\hline & $\pi$ & B & $\alpha$ & $\mathbf{R}^{2}$ & \\
\hline aza-BODIPY 1 & $0.133 \pm 0.172$ & $-0.106 \pm 0.171$ & $-0.034 \pm 0.148$ & 0.101 & \\
\hline aza-BODIPY 2 & $0.248 \pm 0.353$ & $-0.755 \pm 0.357$ & $-0.006 \pm 0.319$ & 0.425 & \\
\hline aza-BODIPY 3 & $0.238 \pm 0.168$ & $-0.494 \pm 0.168$ & $-0.332 \pm 0.145$ & 0.767 & \\
\hline \multicolumn{6}{|c|}{ Catalan Parameters' Regression } \\
\hline & SP & SPP & SA & SB & $\mathbf{R}^{2}$ \\
\hline aza-BODIPY 1 & $0.702 \pm 0.762$ & $-0.054 \pm 0.206$ & $-0.152 \pm 0.342$ & $0.097 \pm 0.312$ & 0.234 \\
\hline aza-BODIPY 2 & $3.126 \pm 1.138$ & $-0.211 \pm 0.309$ & $0.588 \pm 0.516$ & $-0.709 \pm 0.471$ & 0.743 \\
\hline aza-BODIPY 3 & $1.078 \pm 0.628$ & $-0.019 \pm 0.170$ & $-0.639 \pm 0.282$ & $-0.331 \pm 0.257$ & 0.860 \\
\hline
\end{tabular}

\section{Conclusions}

The spectral properties of a number of aza-BODIPYs, complexes 1-3, differing in their natures and functional substituents at the periphery, were studied under the conditions of varying the nature of the individual solvent.

Using the studied compounds as an example, the relationship between the structure and spectral properties of aza-BODIPY dyes was shown. In particular, the substitution of nitrogen for the meso-carbon atom and the introduction of thienyl substituents into the structure led to a shift of the spectra to the near-infrared region and an increase in the Stokes' shifts due to an increase in the geometric lability of the compounds.

The analysis of aza-BODIPY solvatochromism by a semiempirical approach according to Liptey's theory showed that dyes have a low sensitivity to solvent polarity. Despite the fact that the absorption and fluorescence maxima had a pronounced redshift, the change in the Stokes' shift was insignificant. Nevertheless, we can conclude that weak positive solvatochromism was realized for aza-BODIPYs 1-3.

The decay curves of the excited state of the compounds under study were recorded in a number of organic solvents by the method of time-resolved spectroscopy. It was shown that the curves of the decay of the excited state of molecules did not differ in gradient with a change in the detection wavelength, indicating the absence of significant changes in the geometry of the molecule in the ground and excited states and the implementation of one vertical transition upon excitation.

Thus, the proposed structures can be used as promising scaffolds in the design of optically active devices for sensing and bioimaging. They cover a wide spectrum of wavelengths from $600-750 \mathrm{~nm}$, are inert to the nature of the solvation environment, and exhibit good fluorescence characteristics. The proposed structures are insoluble in water, but can be used in mixed water-dimethyl sulfoxide systems to increase solubility, which 
will also prevent their washout during long-term observations in cells. Increasing the solubility in water can also be considered as a promising direction for further studies of this group of compounds. Thus, the compounds, based on amino-phenyl-substituted dyes, pyridine-substituted dyes, and complexes with substituents bearing quaternated nitrogen, may be of interest in this regard.

Author Contributions: Conceptualization, D.M. and O.V.; methodology, Y.M. and F.T.; software, F.T.; validation, P.M. and N.Y.; formal analysis, P.M.; investigation, D.M. and O.V.; writing —original draft preparation, D.M.; writing-review and editing, Y.M. funding acquisition, Y.M. All authors have read and agreed to the published version of the manuscript.

Funding: This research was partially funded with the support of the scholarship of the President of the Russian Federation for young scientists and graduate students carrying out promising research and development in priority areas of modernization of the Russian economy for 2021-2023 (SP-5338.2021.4) in the part of aza-BODIPY synthesis, and the work was supported by the Russian Science Foundation (Grant No. 19-73-10107) in the part of the aza-BODIPY solvatochromism evaluation and prediction, and by the State Assignment of the Russian Federation (Theme No. 0706-2020-0020) in the part of the time-resolved fluorescence investigation.

Institutional Review Board Statement: Not applicable.

Informed Consent Statement: Not applicable.

Data Availability Statement: Not applicable.

Acknowledgments: The study was carried out using the resources of the Center for Shared Use of Scientific Equipment of the ISUCT (with the support of the Ministry of Science and Higher Education of Russia, Grant No. 075-15-2021-671) and using the equipment of the Shared Science and Training Center for Collective Use RTU MIREA (with the support of the Ministry of Science and Higher Education of Russia, Grant No. 075-15-2021-689, unique identification number: 2296.61321X0010).

Conflicts of Interest: The authors declare no conflict of interest.

\section{References}

1. Zhang, S.; Wu, T.; Fan, J.; Li, Z.; Jiang, N.; Wang, J.; Dou, B.; Sun, S.; Song, F.; Peng, X. A BODIPY-based fluorescent dye for mitochondria in living cells, with low cytotoxicity and high photostability. Org. Biomol. Chem. 2013, 11, 555-558. [CrossRef] [PubMed]

2. Vodyanova, O.S.O.S.; Kochergin, B.A.B.A.; Usoltsev, S.D.S.D.; Marfin, Y.S.Y.S.; Rumyantsev, E.V.E.V.; Aleksakhina, E.L.E.L.; Tomilova, I.K.I.K. BODIPY dyes in bio environment: Spectral characteristics and possibilities for practical application. J. Photochem. Photobiol. A Chem. 2018, 350, 44-51. [CrossRef]

3. Marfin, Y.S.; Solomonov, A.V.; Timin, A.S.; Rumyantsev, E.V. Recent advances of individual BODIPY and BODIPY-based functional materials in medical diagnostics and treatment. Curr. Med. Chem. 2017, 24, 2745-2772. [CrossRef] [PubMed]

4. Mironov, A.F.; Ostroverkhov, P.V.; Tikhonov, S.I.; Pogorilyy, V.A.; Kirin, N.S.; Chudakova, O.O.; Tsygankov, A.A.; Grin, M.A. Amino acid derivatives of natural chlorins as a platform for the creation of targeted photosensitizers in oncology. Fine Chem. Technol. 2021, 15, 16-33. [CrossRef]

5. Bhate, D.; Penick, C.; Ferry, L.; Lee, C. Classification and Selection of Cellular Materials in Mechanical Design: Engineering and Biomimetic Approaches. Designs 2019, 3, 19. [CrossRef]

6. Bhasin, D.; McAdams, D. The Characterization of Biological Organization, Abstraction, and Novelty in Biomimetic Design. Designs 2018, 2, 54. [CrossRef]

7. Nagel, J.; Schmidt, L.; Born, W. Establishing Analogy Categories for Bio-Inspired Design. Designs 2018, 2, 47. [CrossRef]

8. Melnikov, P.V.; Alexandrovskaya, A.Y.; Naumova, A.O.; Popova, N.M.; Spitsyn, B.V.; Zaitsev, N.K.; Yashtulov, N.A. Modified Nanodiamonds as a Means of Polymer Surface Functionalization. From Fouling Suppression to Biosensor Design. Nanomaterials 2021, 11, 2980. [CrossRef]

9. Alexandrovskaya, A.Y.; Melnikov, P.V.; Safonov, A.V.; Naumova, A.O.; Zaytsev, N.K. A comprehensive study of the resistance to biofouling of different polymers for optical oxygen sensors. The advantage of the novel fluorinated composite based on core-dye-shell structure. Mater. Today Commun. 2020, 23, 100916. [CrossRef]

10. Melnikov, P.V.; Kozhukhova, A.E.; Naumova, A.O.; Yashtulov, N.A.; Zaitsev, N.K. Optical analyzer for continuous monitoring of dissolved oxygen in aviation fuel and other non-aqueous media. Int. J. Eng. 2019, 32, 641-646. [CrossRef]

11. Aleksandrovskaya, A.Y.; Melnikov, P.V.; Safonov, A.V.; Abaturova, N.A.; Spitsyn, B.V.; Naumova, A.O.; Zaitsev, N.K. The Effect of Modified Nanodiamonds on the Wettability of the Surface of an Optical Oxygen Sensor and Biological Fouling During Long-Term in Situ Measurements. Nanotechnol. Russ. 2019, 14, 389-396. [CrossRef] 
12. Goncharenko, A.A.; Tarasyuk, I.A.; Marfin, Y.S.; Grzhegorzhevskii, K.V.; Muslimov, A.R.; Bondarenko, A.B.; Lebedev, M.D.; Kuz'min, I.A.; Vashurin, A.S.; Lepik, K.V.; et al. DDAO controlled synthesis of organo-modified silica nanoparticles with encapsulated fluorescent boron dipyrrins and study of their uptake by cancerous cells. Molecules 2020, 25, 3802. [CrossRef] [PubMed]

13. Marfin, Y.S.; Vodyanova, O.S.O.S.; Merkushev, D.A.D.A.; Usoltsev, S.D.S.D.; Kurzin, V.O.V.O.; Rumyantsev, E.V.E.V. Effect of $\pi$-Extended Substituents on Photophysical Properties of BODIPY Dyes in Solutions. J. Fluoresc. 2016, 26, 1975-1985. [CrossRef] [PubMed]

14. Marfin, Y.S.; Aleksakhina, E.L.; Merkushev, D.A.; Rumyantsev, E.V.; Tomilova, I.K. Interaction of BODIPY Dyes with the Blood Plasma Proteins. J. Fluoresc. 2016, 26, 255-261. [CrossRef] [PubMed]

15. Qi, S.; Kwon, N.; Yim, Y.; Nguyen, V.N.; Yoon, J. Fine-tuning the electronic structure of heavy-atom-free BODIPY photosensitizers for fluorescence imaging and mitochondria-targeted photodynamic therapy. Chem. Sci. 2020, 11, 6479-6484. [CrossRef] [PubMed]

16. Prieto-Montero, R.; Prieto-Castañeda, A.; Sola-Llano, R.; Agarrabeitia, A.R.; García-Fresnadillo, D.; López-Arbeloa, I.; Villanueva, A.; Ortiz, M.J.; de la Moya, S.; Martínez-Martínez, V. Exploring BODIPY Derivatives as Singlet Oxygen Photosensitizers for PDT. Photochem. Photobiol. 2020, 96, 458-477. [CrossRef]

17. Marfin, Y.S.; Banakova, E.A.; Merkushev, D.A.; Usoltsev, S.D.; Churakov, A.V. Effects of Concentration on Aggregation of BODIPY-Based Fluorescent Dyes Solution. J. Fluoresc. 2020, 30, 1611-1621. [CrossRef]

18. Chen, Y.; Tsao, K.; Acton, S.L.; Keillor, J.W. A Green BODIPY-Based, Super-Fluorogenic, Protein-Specific Labelling Agent. Angew. Chemie Int. Ed. 2018, 57, 12390-12394. [CrossRef]

19. Bumagina, N.A.; Kritskaya, A.Y.; Antina, E.V.; Berezin, M.B.; V'yugin, A.I. Effect of Alkyl, Aryl, and meso-Aza Substitution on the Thermal Stability of BODIPY. Russ. J. Inorg. Chem. 2018, 63, 1326-1332. [CrossRef]

20. Wang, M.; Vicente, M.G.H.; Mason, D.; Bobadova-Parvanova, P. Stability of a Series of BODIPYs in Acidic Conditions: An Experimental and Computational Study into the Role of the Substituents at Boron. ACS Omega 2018, 3, 5502-5510. [CrossRef]

21. Liu, M.; Ma, S.; She, M.; Chen, J.; Wang, Z.; Liu, P.; Zhang, S.; Li, J. Structural modification of BODIPY: Improve its applicability. Chin. Chem. Lett. 2019, 30, 1815-1824. [CrossRef]

22. Kamkaew, A.; Burgess, K. Aza-BODIPY dyes with enhanced hydrophilicity. Chem. Commun. 2015, 51, 10664-10667. [CrossRef] [PubMed]

23. Krajcovicova, S.; Stankova, J.; Dzubak, P.; Hajduch, M.; Soural, M.; Urban, M. A Synthetic Approach for the Rapid Preparation of BODIPY Conjugates and their use in Imaging of Cellular Drug Uptake and Distribution. Chem. A Eur. J. 2018, 24, $4957-4966$. [CrossRef]

24. Gayathri, T.; Karnewar, S.; Kotamraju, S.; Singh, S.P. High Affinity Neutral Bodipy Fluorophores for Mitochondrial Tracking. ACS Med. Chem. Lett. 2018, 9, 618-622. [CrossRef] [PubMed]

25. Liao, J.; Zhao, H.; Cai, Z.; Xu, Y.; Qin, F.G.F.; Zong, Q.; Peng, F.; Fang, Y. BODIPY-based panchromatic chromophore for efficient organic solar cell. Org. Electron. 2018, 61, 215-222. [CrossRef]

26. Merkushev, D.A.; Usoltsev, S.D.; Marfin, Y.S.; Pushkarev, A.P.; Volyniuk, D.; Grazulevicius, J.V.; Rumyantsev, E.V. BODIPY associates in organic matrices: Spectral properties, photostability and evaluation as OLED emitters. Mater. Chem. Phys. 2016, 187, 104-111. [CrossRef]

27. Kursunlu, A.N.; Baslak, C. A Bodipy-bearing pillar[5]arene for mimicking photosynthesis: Multi-fluorophoric light harvesting system. Tetrahedron Lett. 2018, 59, 1958-1962. [CrossRef]

28. Rani, K.; Pandey, U.K.; Sengupta, S. Efficient electron transporting and panchromatic absorbing FRET cassettes based on azaBODIPY and perylenediimide towards multiple metal FRET-Off sensing and ratiometric temperature sensing. J. Mater. Chem. C 2021, 9, 4607-4618. [CrossRef]

29. Vyšniauskas, A.; Cornell, B.; Sherin, P.S.; Maleckaitè, K.; Kubánková, M.; Izquierdo, M.A.; Vu, T.T.; Volkova, Y.A.; Budynina, E.M.; Molteni, C.; et al. Cyclopropyl Substituents Transform the Viscosity-Sensitive BODIPY Molecular Rotor into a Temperature Sensor. ACS Sensors 2021, 6, 2158-2167. [CrossRef]

30. Wang, Q.; Ng, D.K.P.; Lo, P.C. Functional aza-boron dipyrromethenes for subcellular imaging and organelle-specific photodynamic therapy. J. Mater. Chem. B 2018, 6, 3285-3296. [CrossRef]

31. Liu, S.; Shi, Z.; Xu, W.; Yang, H.; Xi, N.; Liu, X.; Zhao, Q.; Huang, W. A class of wavelength-tunable near-infrared aza-BODIPY dyes and their application for sensing mercury ion. Dye. Pigment. 2014, 103, 145-153. [CrossRef]

32. Strobl, M.; Rappitsch, T.; Borisov, S.M.; Mayr, T.; Klimant, I. NIR-emitting aza-BODIPY dyes-new building blocks for broad-range optical pH sensors. Analyst 2015, 140, 7150-7153. [CrossRef]

33. Cao, K.J.; Elbel, K.M.; Cifelli, J.L.; Cirera, J.; Sigurdson, C.J.; Paesani, F.; Theodorakis, E.A.; Yang, J. Solvation-Guided Design of Fluorescent Probes for Discrimination of Amyloids. Sci. Rep. 2018, 8, 6950. [CrossRef]

34. Melo, C.E.A.; Nandi, L.G.; Domínguez, M.; Rezende, M.C.; Machado, V.G. Solvatochromic behavior of dyes with dimethylamino electron-donor and nitro electron-acceptor groups in their molecular structure. J. Phys. Org. Chem. 2015, 28, 250-260. [CrossRef]

35. Filarowski, A.; Lopatkova, M.; Lipkowski, P.; van der Auweraer, M.; Leen, V.; Dehaen, W. Solvatochromism of BODIPY-Schiff dye. J. Phys. Chem. B 2015, 119, 2576-2584. [CrossRef] [PubMed]

36. Stock, R.I.; de Melo, C.E.A.; Schramm, A.D.S.; Nicoleti, C.R.; Bortoluzzi, A.J.; Heying, R.d.S.; Machado, V.G.; Rezende, M.C. Structure-behavior study of a family of "hybrid cyanine" dyes which exhibit inverted solvatochromism. Phys. Chem. Chem. Phys. 2016, 18, 32256-32265. [CrossRef] 
37. González-Vera, J.A.; Lv, F.; Escudero, D.; Orte, A.; Guo, X.; Hao, E.; Talavera-Rodriguez, E.M.; Jiao, L.; Boens, N.; Ruedas-Rama, M.J. Unusual spectroscopic and photophysical properties of solvatochromic BODIPY analogues of Prodan. Dye. Pigment. 2020, 182, 108510. [CrossRef]

38. Duereh, A.; Anantpinijwatna, A.; Latcharote, P. Prediction of solvatochromic polarity parameters for aqueous mixed-solvent systems. Appl. Sci. 2020, 10, 8480. [CrossRef]

39. Kadam, M.M.L.; Patil, D.; Sekar, N. Carbazole based NLOphoric styryl dyes- synthesis and study of photophysical properties by solvatochromism and viscosity sensitivity. J. Lumin. 2018, 202, 212-224. [CrossRef]

40. Sot, J.; Esnal, I.; Monasterio, B.G.; León-Irra, R.; Niko, Y.; Goñi, F.M.; Klymchenko, A.; Alonso, A. Phase-selective staining of model and cell membranes, lipid droplets and lipoproteins with fluorescent solvatochromic pyrene probes. Biochim. Biophys. Acta Biomembr. 2021, 1863, 183470. [CrossRef]

41. Telegin, F.Y.; Marfin, Y.S. New insights into quantifying the solvatochromism of BODIPY based fluorescent probes. Spectrochim. Acta Part A Mol. Biomol. Spectrosc. 2021, 255, 119683. [CrossRef]

42. Zhang, D.; Xu, N.; Xian, L.; Ge, H.; Fan, J.; Du, J.; Peng, X. A BODIPY-based Fluorescent Probe for Thiophenol. Chin. J. Chem. 2018, 36, 119-123. [CrossRef]

43. Aleksakhina, E.L.; Pakhrova, O.A.; Tomilova, I.K.; Merkushev, D.A.; Molchanov, E.E.; Usoltsev, S.D.; Vodyanova, O.S.; Marfin, Y.S. Comparative In Vitro Analysis Of Cytotoxicity Of Bodipy-Luminophers As Potential Fluorescent Sensors For Biological Systems. ChemChemTech 2021, 64, 13-23. [CrossRef]

44. Marfin, Y.; Merkushev, D.; Khalabudin, D. Fast Synthesis of Tetra-Aryl-Substituted Aza-BODIPYs. Proc. J. Phys. Conf. Ser. 2021, 1822, 012004. [CrossRef]

45. Gresser, R.; Hartmann, H.; Wrackmeyer, M.; Leo, K.; Riede, M. Synthesis of thiophene-substituted aza-BODIPYs and their optical and electrochemical properties. Tetrahedron 2011, 67, 7148-7155. [CrossRef]

46. Kamlet, M.J.; Abboud, J.L.M.; Abraham, M.H.; Taft, R.W. Linear Solvation Energy Relationships. 23. A Comprehensive Collection of the Solvatochromic Parameters, $\pi, \alpha$, and $\beta$, and Some Methods for Simplifying the Generalized Solvatochromic Equation. $J$. Org. Chem. 1983, 48, 2877-2887. [CrossRef]

47. Catalán, J. Toward a generalized treatment of the solvent effect based on four empirical scales: Dipolarity (SdP, a new scale), polarizability (SP), acidity (SA), and basicity (SB) of the medium. J. Phys. Chem. B 2009, 113, 5951-5960. [CrossRef]

48. Solomonov, A.; Marfin, Y. Self-assembling triton-based micellar clusters: Formation features and modification strategies for new functional materials creation. In Proceedings of the 42nd Congress of the Federation-of-European-Biochemical-Societies (FEBS) on From Molecules to Cells and Back, Jerusalem, Israel, 10-14 September 2017.

49. Koch, A.; Kumar, S.; Ravikanth, M. Synthesis and Properties of B(Ph)(OR) Complexes of Azadipyrrin. Eur. J. Org. Chem. 2018, 2018, 4277-4283. [CrossRef]

50. Zhang, X.; Yu, H.; Xiao, Y. 2012 Replacing phenyl ring with thiophene an approach to longer wavelength aza-dipyrromethene boron difluoride (Aza-BODIPY) dyes. J. Org. Chem. 2012, 77, 669-673. [CrossRef]

51. Loudet, A.; Burgess, K. BODIPY Dyes and Their Derivatives: Syntheses and Spectroscopic Properties. Chem. Rev. 2007, 107, 4891-4932. [CrossRef] 